\title{
Problems and Countermeasures of Cultivating Excellent Students in Our Country
}

\author{
Jiali Ma, Shanliang He \\ Institute of Curriculum and Teaching, Nanjing Normal University, Nanjing, China \\ Email: 2982956654@qq.com
}

How to cite this paper: Ma, J. L., \& He, S. L. (2020). Problems and Countermeasures of Cultivating Excellent Students in Our Country. Open Journal of Social Sciences, 8, 471-481.

https://doi.org/10.4236/jss.2020.83039

Received: March 10, 2020

Accepted: March 28, 2020

Published: March 31, 2020

\begin{abstract}
Gifted students refer to students with medium intelligence or above, good personality and development expertise and potential in some aspects. As a reserve force for high-end talents, the cultivation of gifted students is of national strategic significance and is also a kind of human concern for the individual values of gifted students. At present, there are many problems in the concept definition, policy guarantee, selection mechanism, curriculum and teaching of gifted students' education in our country. The solution of these problems not only needs to get rid of people's prejudice on gifted education, but also needs systematic changes in the selection policies, training programs and teacher training of gifted students.
\end{abstract}

\section{Keywords}

Gifted Students, Cultivating Gifted Students, Special Needs Education

\section{Introduction}

The competition in the future world is not only for resources, but also for talents, especially for high-end talents and high-quality top-notch talents. China has been developing at a high speed for many years. All countries in the world are concerned about how long China can develop. One of the core driving forces for rapid and sustained development is talent. In particular, China is currently undergoing a period of transformation from labor-intensive to technology-intensive, and training top-notch innovative leaders is even more critical (Liu, 2018). On the contrary, there are many problems in gifted education for cultivating high-end talents in China (Sun, 2018), which are all worthy of our attention and solution. As a kind of social practice activity to train people, how to train high-end talents and high-quality top-notch talents in education and how to pay attention to the education and training of gifted students have be- 
come problems that cannot be bypassed by educational theory researchers, educational policy makers and educational practitioners. Under this background, it is of great practical significance to focus on the problems and countermeasures in the cultivation of gifted students in our country.

\section{The Definition of Gifted Students and the Significance of Their Cultivation}

The research on gifted students has been going on for many years in our country. Early scholars mainly believed that "gifted students are gifted children and children with exceptional IQ (IQ over 130)." This definition focuses on the intelligence factors of gifted students and emphasizes their IQ. However, with the development of education, psychology and other disciplines, people realize that there is a difference between gifted students and gifted students. Gifted students include gifted IQ, but not only gifted IQ. There are three conditions for gifted students: 1) moderate intelligence (IQ > 120);2) having good personality and psychological quality (high thirst for knowledge, strong sense of responsibility, good independence of self-control, strong competitive heart); 3) Be creative and like to concentrate thinking and divergent thinking. In 1972, the US Congress also presented the famous Mahlander Report. The report pointed out that the gifted individual should be characterized by remarkable ability and potential in one or more of the following fields: general ability, special academic ability tendency, creative thinking ability, leadership ability, visual and performing arts, and psychomotor ability (Wikipedia, 2017). Therefore, this article thinks that the gifted students in our country mainly refer to students with medium intelligence or above, good personality and development expertise and potential in some aspects.

The importance of talents to national development is self-evident. China's "Outline of National Medium-and Long-Term Education Reform and Development Plan" points out that talents training mode should be innovated to meet the needs of national and social development. It should follow the laws of education and talents growth, deepen education and teaching reform, innovate education and teaching methods, explore various training methods, and form a situation in which all kinds of talents come forth in large numbers and top-notch innovative talents emerge continuously. (Min Zhao, 2018) Research and statistics by psychologists from various countries show that about $3 \%$ of primary and secondary school students have exceptional intelligence. According to this proportion, there are at least millions of children with high intelligence quotient in our country. This potential talent advantage should not be ignored. developing these students is an effective way to cultivate innovative talents. In schools and society, we will see many "innovative experimental classes" and "excellent training classes". Our country has also set up a children's department since the Tang Dynasty. Until modern times, our great educator Tao Xingzhi also set up a Yucai Middle School, and then the establishment of a modern HKUST children's class. We can see that great importance has been attached to the cultivation of gifted 
students from ancient times to present. Then why should we attach importance to the cultivation of gifted students?

\subsection{Gifted Students Are More Likely to Contribute to the Development of the Country and Society}

With the development of modern science and technology and the progress of education, the world's consumption of resources is increasing. In the future, the world's competition will not only be for resources, but more for talents, especially for high-end talents and high-quality top-notch talents. The cultivation of talented students has long been the focus of every country's attention. Finland, the United States, Japan, Singapore and other countries have invested a lot of energy in the training of these talents. The reason is that the training of top-notch talents is the need of national development, and these talents are also the main force of future international competition. Countries that take priority in the talent market will be given priority in the future world competition, which will further encourage countries around the world to increase the training of high-quality top-notch talents.

Qian Xuesen, Einstein and others are leaders in different fields, and at the same time promote social progress. The common characteristics of these people are high IQ, creativity and perseverance, and these characteristics are what gifted students have. Compared with other people, gifted students are more likely to contribute to social development. If we can find these gifted students as early as possible and cultivate them, they can better realize their self-development and make their own contribution to social progress.

\subsection{The State and Society Should Give Gifted Students More Care for Their Personal Values}

In recent decades, educational theory and practice have developed rapidly. On the one hand, the theory of gifted education is maturing and improving, such as multiple intelligence theory, differential teaching theory, dual gifted education theory, innovative talents theory, etc., which provide a solid theoretical basis for gifted education research. On the other hand, school teaching has changed from "subject-based" to "student-based" and the student's dominant position has been taken seriously. In the past, the disadvantages of "factory-based" teaching have become more and more obvious. People from all walks of life are calling for more and more individualized teaching for students. The state supports more and more differential teaching and special education, which provides practical support for gifted education. On this basis, it is imperative to pay more attention to gifted education.

However, what is more important is that gifted students are superior to ordinary people in intelligence quotient and have potential different from ordinary people in some aspects. They are generally ambitious, eager to learn, good at special research, receptive and motivated. They require more in-depth knowledge learning. The knowledge taught in ordinary teaching will make them lack 
interest or sense of achievement, obliterate their strengths and hinder their growth. As a result, they cannot find their potential in learning, cannot get the development they deserve, and their development is hindered, which also leads to the loss of talents in our country. Therefore, the state and society should pay more attention to gifted students so that their personal life value can be properly developed.

As a result, we have to think about the problems faced by our state-owned gifted students at this stage.

\section{The Problems Existing in Our State-Owned Gifted Education}

All countries are paying attention to the cultivation of gifted students. Compared with the emphasis on gifted education in the United States, the emphasis on gifted education in our country is far from enough. Therefore, there are more problems to be solved in our state-owned gifted education.

\subsection{The Selection Mechanism Is Not Unified and Lacks the Protection of National Policies}

How to select gifted students? This problem has always been the concern of all countries. At present, judging from the selection of gifted students in our country, the selection mechanism is not unified, the selection form is single, and the selection area is unbalanced. In the selection mechanism, China has not promulgated uniform policies, laws and regulations. Different regions have different definitions of gifted students, resulting in different selection mechanisms. This makes the gifted students selected in different regions have great differences and uneven levels. In the form of selection, the selection of gifted students in most areas is limited to intelligence tests and academic tests. Most teachers think that students with high IQ and excellent results are gifted students. This phenomenon reflects to a certain extent the vague definition of gifted students and the lack of research on gifted education in China. In different regions, because there is no uniform selection standard, some regions will adopt a recommendation system, with schools or parents recommending students to take gifted students' exams. The advantage of this kind of selection is that the selection of gifted students is more focused, without spending a lot of time, manpower and financial resources to search everywhere. However, this kind of selection also makes it difficult to find gifted students in backward areas, resulting in uneven regional development.

Educators abroad have been paying attention to the positive effect of policy guarantee on gifted students' education. The article "A Review on Indonesia Policy in Supporting Gifted Students Education" mentioned that if the government takes gifted students seriously and gives them the best attention and service, it is no longer a difficult problem for gifted students to be neglected in education (Setiawan \& Septiarti, 2019). The current situation in our country happens to be that our policy does not pay too much attention to gifted educa- 
tion. The main reasons may be the following two points: First, although some educational decision makers have been paying attention to gifted education, educational decision makers do not understand gifted education and seldom fully and successfully view and elaborate gifted education. There is no denying that the emergence of this problem lies in the fact that the research on gifted students in our country is still in its infancy. Second, the definition, selection and teaching of gifted students by Chinese scholars are still superficial. The government can issue more effective policies only when the educators in our country make more in-depth research on gifted students. However, the research on gifted students must first be supported by the government, which forms a vicious circle. Breaking this vicious circle requires government decision makers to actively promulgate policies to support gifted education to encourage educators to study gifted education.

\subsection{The Chinese People Have a Deep Misunderstanding of Gifted Education}

In our country, the education of gifted students is always kept secret. The relevant policies for gifted education are basically zero, and the selection and education of gifted students in various regions are also basically few. A few gifted education schools or classes are also considered "pinching the sharp points". Most people have a great degree of doubt and misunderstanding about gifted education. One is to link gifted education with educational equity, believing that the development of gifted education is detrimental to equity; the second is that extraordinary development hinders the healthy development of children's personality and deprives "child prodigies" of their childhood. The third is that people can become talents through hard work. They do not recognize gifted children or gifted children can become outstanding talents without special training. (Wei Zhou, 1998) These people mistakenly understand gifted education as "elite" education which is only measured by academic performance. This reflects the lack of popularization of the concept, policy and significance of gifted education in our country. Its root lies in the lack of state support and affirmation for gifted education.

On the premise that gifted education is protected and supported by the U.S. government and laws, there are still many unsolved problems. China has not clearly stated the importance of gifted education in its policies, nor has there been a unified standard for the selection of gifted students, nor has there been a specific curriculum and teaching content. In a few policies and documents, it only emphasizes the importance of special education, focusing on special children (the disabled, the disabled, etc.), and has spent a lot of resources on special children, while gifted students belonging to special children can only waste a lot of time in ordinary schools and cannot obtain special and high-quality education that is suitable for their physical and mental characteristics. Therefore, this misunderstanding of gifted students and the lack of policies and documents have seriously hindered the development of gifted student education in our country. 


\subsection{Gifted Students Curriculum and Teaching Content Is Seriously Missing}

Some schools in our country are also trying to carry out gifted education, such as tianyi middle school in Jiangsu Province. In the process of educating gifted students, the first question is: what is the curriculum for these children? What are the teaching contents and principles? Some schools have put forward the goal of "bringing in talented people early, bringing in talented people quickly and bringing in good ones". In order to achieve this goal, they cut down on subjects and extend teaching hours in order to reach younger and older grades. This kind of behavior that encourages young people is against the laws of education. The curriculum design for gifted students should have been paid more attention to, but at present it has evolved into the merger and acceleration of ordinary courses. Some so-called gifted students' courses have not been designed according to the characteristics of gifted students themselves, but have merged various subjects into a "hodgepodge" and forced them to absorb them all.

We should realize that the cultivation of gifted students should create a superior educational environment for them in the middle school stage, so that they can receive good training from an early age, develop, cultivate early, develop a complete knowledge structure, master scientific learning methods, cultivate tenacious perseverance, and have healthy psychological quality and social ability. Strengthening research and development of gifted students' courses and teaching contents is the focus of gifted students' education.

\subsection{A Large Number of Outstanding Gifted Teachers Lack}

In our country, the school supernormal education with class teaching system as its main form of education has been in our country for many years, but many teachers are still not familiar with this form. Most teachers still use traditional educational ideas and teaching methods to implement gifted students' education, which will eventually lead to the disappearance of gifted students' personality and psychological characteristics and all the people. Such a teacher is a failure to educate gifted students. However, most of the teachers engaged in gifted education in our country are selected from teachers in ordinary schools. They generally have no special training for gifted students. On the one hand, this is not conducive to the teaching of gifted students. Education for gifted students is different from general education, which requires teachers to carry out targeted teaching according to the individual characteristics of gifted students and their learning interests and characteristics. If teachers do not have enough ability to grasp the overall situation, it is difficult to give full play to the real role of gifted education. On the other hand, it is not conducive to the development of teachers. The teaching of gifted students is a challenge to teachers. Without special training or support from schools and the government, it is difficult for teachers to improve their own development, and it is easier to slack off and neglect the teaching of gifted students. 
The more important reason is that the state has not issued corresponding professional standards for teachers. For example, professional standards should be specified to improve teachers' teaching ability and meet the specific learning needs of gifted students. In the absence of professional standards, teachers cannot fully understand students' own situation and their learning methods, nor do they know what abilities and standards they should have as gifted and gifted teachers.

\section{Gifted Students Education Problem Solving Strategy}

Solving the problems faced by gifted education is the most crucial step in the progress of gifted education. In view of the problems faced by gifted education in our country, this paper puts forward the following four solutions.

\subsection{Get Rid of People's Prejudice against Gifted Education}

Educational equity has been a basic education policy in our country for many years. Educational equity is the basic requirement of education policy. Educational equity in its developmental sense means providing each student with appropriate education and paying more attention to the educational process and results. On the principle of differentiation of educational fairness, providing students with education suitable for their personality and interests and education suitable for their own ability level is the main purpose of the principle of differentiation. The biggest mistake in teaching is "to treat all children as if they were the same individual with no difference, and to teach the same subject in the same way" (Gu, 2007). The real fairness is not "unity", but "seeking differences" based on the degree of differentiation principle.

At present, the problem of gifted students' education mentioned by the Chinese people is essentially a lack of understanding of educational fairness. In order to eliminate the voices of misunderstanding, the most important thing is for the public to re-examine the fairness of education and understand that school education does not only emphasize unity but also does not lag behind. School education should move towards quality and balanced education and should encourage coexistence of various forms of education, such as gifted education. Therefore, the education department should expand gifted education and develop gifted education through laws, regulations, literature research and other channels. Schools should also pay attention to students with gifted students in their daily teaching and teach them in accordance with their aptitude. Parents should also understand the importance of teaching students according to their aptitude for the growth of each child and the importance of gifted students for the future strategic development of our country.

\subsection{Promulgating as Soon as Possible a Standardized and Unified Selection Policy for Gifted Students}

Accurate positioning and profound understanding of things are undoubtedly beneficial for us to establish the direction of action and grasp the characteristics 
of things. Based on the previous discussion on gifted students, we can see that the first thing to cultivate gifted students is to define gifted students clearly and adopt a unified standard for the selection of gifted students nationwide. The definition of gifted students varies from country to country, from region to region and from culture to culture. The gifted education based on China's national conditions and culture is undoubtedly more suitable for the development of gifted education in our country. According to the state-owned eugenics education, the following measures are put forward: first, unify the definition of eugenics. In order to fully understand the state-owned gifted education in our country and increase and deepen the research on gifted education, colleges and universities can set up gifted education research groups, organize relevant experts to carry out research and development on current policies, current situation, international exchanges, courses, etc., sum up experience and propose the definition of gifted students on the basis of fully understanding the current situation in our country. Second, unify the selection criteria for gifted students in our country. The selection of gifted students is the basis of gifted education. What age group of children should be selected? What are the criteria for selection? This should be carefully considered. The selection of gifted students should adopt a variety of test methods and test contents, carry out selection and identification from multiple angles and multiple indicators, and be more objective, scientific and effective in selection. Based on this principle, a unified national selection standard should be set up to prevent the phenomenon of "rational and gifted land". Third, relevant policies and regulations should be promulgated as soon as possible to establish funds for gifted students. We will begin to consider the drafting of laws and regulations on gifted education so as to teach under the rule of law and prevent the impact and interference of human factors. At the same time, the formulation of laws and regulations helps the society to recognize and implement gifted education. The establishment of "gifted education" special funds to support the research and development of gifted education and support. Let every gifted student be discovered as soon as possible and discover his potential as soon as possible.

\subsection{To Develop a Special Talent Training Program for Gifted Students}

Psychological research results show that early environment will have a profound impact on brain development. If we can carry out early education in a timely manner in the plastic period of the nervous system, everyone's potential can be better developed, especially for gifted students. At present, there is no special talent training program for gifted students in our country. For gifted students, education is more about simply speeding up or pulling away the curriculum so that gifted students can learn more and faster. The disadvantage of this approach is that although students learn a lot of knowledge in a short period of time, they are extremely prone to psychological problems due to their young psychological age. 
According to the current situation in our country, the first task is to formulate a special talent training program. Curriculum setting, curriculum content and teaching practice can be listed as key points in the talent training plan. First, try to get rid of the shackles of the current examination system and make the curriculum standard setting and evaluation for gifted and gifted children more flexible. Curriculum standards should be more flexible to ensure gifted students can accept inspiring, rich and thought-provoking courses. In terms of evaluation, standardized tests are prevented from being used as the main evaluation method unilaterally, and various methods and methods are emphasized, such as learning diary, self-evaluation questionnaire, portfolio and other methods for evaluation. Second, the curriculum content should be appropriately accelerated based on the laws of children's physical and mental development. In recent years, some scholars have investigated the influence of different course contents on students' performance. After evaluating the effect quantity in statistical measurement, it is found that the relative effect quantity of acceleration (early in and early out, content-based acceleration, compression of learning time, skip grade, double registration, etc.), course compression, grouping (grouping according to ability, classification and selection, complete grouping based on ability, clustering grouping and independent working grouping) is higher based on content acceleration, course compression and clustering grouping. From this, we can also find that the content of gifted students' curriculum should be based on the promotion and divergence of the curriculum foundation. Excessive emphasis on accelerating the construction of gifted students' knowledge is not conducive. Only by combining the acceleration based on the discipline foundation with the recent development area of gifted students can their potential be truly stimulated. Third, the teaching practice process focuses on cultivating gifted students' advanced thinking, creative thinking, problem solving and independent or group research. For example, to establish high standards for all gifted students in the class; Adjust the curriculum to improve the level of challenges; Teachers provide guidance in areas where gifted students have a strong interest; Encourage students to complete projects independently as often as possible; Create flexible teaching groups to keep students interested and keep them involved (Sousa, 2005: p. 189).

\subsection{To Strengthen the Training of Gifted Teachers}

High-quality, professional and innovative teachers are the key to the implementation of gifted education. Teachers are indispensable to the whole process of gifted education. The role of teachers is not only to impart the rich knowledge accumulated by human beings to students, but also to cultivate students' ability, so that students have noble moral character and form good personality. We must realize that the selection and training of gifted teachers is the responsibility of all teachers, not a few. Therefore, for the cultivation of gifted teachers, there are four suggestions as follows: First, strictly select suitable gifted teachers. As 
gifted teachers, they should have certain principles, such as: having teachers' professional ethics, extensive knowledge, strong working ability, innovative spirit and teachers' cooperative consciousness. On this basis, the selection of gifted teachers is the basis for building an excellent teaching team. Second, high-frequency on-the-job training for gifted teachers. There are generally two kinds of training for gifted teachers, on-the-job training and on-the-job training, with on-the-job training as the main training. The frequency of on-the-job training can be decided by the school, but at least three to four times a year is guaranteed. The following aspects should be paid attention to in training: improving teachers' understanding of gifted education, guiding teachers to learn educational theories, organizing teachers to carry out educational research activities, guiding teachers to carry out educational research and hiring experts to make academic reports. Third, education departments should set professional standards for gifted teachers from Taiwan as soon as possible. The introduction of professional standards for teachers is a guarantee for the selection and training of gifted teachers. Without a reference standard, even strict screening and high-frequency training may lead to different local effects, resulting in "geographical differences". Fourth, normal colleges and universities should specially train gifted teachers and train professional teachers from the source. Normal colleges and universities are of great significance to the transportation of national teachers. Normal colleges and universities should shoulder the important task of training all kinds of teachers in our country. As a part of special education, gifted teachers should be accepted and trained like other special education teachers.

\section{Result}

The cultivation of talents is of great significance to the strategic development of the country, and gifted education is very important to the cultivation and accumulation of high-end talents in our country. In order to cultivate gifted students, we must first find out the existing problems in our state-owned gifted education. In the absence of policies and laws and regulations, gifted education is also lacking in curriculum and teachers. Based on these problems, in the future development of gifted education in our country, we should pay attention to formulate relevant policies and regulations in combination with the learning situation in our country, increase the compilation of gifted courses by teachers and relevant scholars, and encourage universities and education departments to train and select gifted teachers. At present, the research on gifted students' education in our country is still at the theoretical stage. In the future research, strengthening the practical research on gifted students' education should become a new research direction.

\section{Conflicts of Interest}

The authors declare no conflicts of interest regarding the publication of this paper. 


\section{References}

Gu, M.-Y. (2007). Teaching Students in Accordance with Their Aptitude and Educational Fairness. Modern University Education, No. 6, 1-3.

Liu, J. (2018). Preface: Selection and Education of Supernormal Talents. Teaching Research, 41, 1-3.

Setiawan, R., \& Septiarti, S. W. (2019). A Review on Indonesia Policy in Supporting Gifted Students Education. In International Conference on Special and Inclusive Education (ICSIE 2018). Atlantis Press. https://doi.org/10.2991/icsie-18.2019.25

Sousa (2005). Genius Brain and Learning (p. 189). China Light Industry Press.

Sun, J. X. (2018). China's Meritocracy Education Reality and Recommendations. People's Political Consultative Conference, 2018-11-21(009).

Wikipedia (2017). hhtp://cn.m.wikipediaorg

Zhao, M. (2018). Training Innovative Talents Needs to Achieve "Four Breakthroughs". China's Higher Education, No. 21, 19-22.

Zhou, W. (1998). Policy Research on Developing Exceptional (Gifted) Education. Modern Special Education, No. 4, 10-12. 